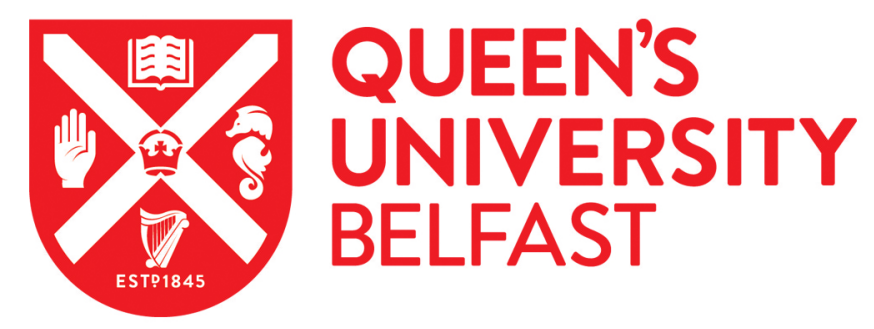

\title{
Effects of autotomy compared to manual declawing on contests between males for females in the edible crab, Cancer pagurus: implications for fishery practice and animal welfare.
}

McCambridge, C., Dick, J., \& Elwood, R. (2016). Effects of autotomy compared to manual declawing on contests between males for females in the edible crab, Cancer pagurus: implications for fishery practice and animal welfare. Journal of Shellfish Research, 35(4), 1037-1044. https://doi.org/10.2983/035.035.0426

Published in:

Journal of Shellfish Research

Document Version:

Peer reviewed version

Queen's University Belfast - Research Portal:

Link to publication record in Queen's University Belfast Research Portal

Publisher rights

Copyright 2016 NSA.

This work is made available online in accordance with the publisher's policies. Please refer to any applicable terms of use of the publisher.

\section{General rights}

Copyright for the publications made accessible via the Queen's University Belfast Research Portal is retained by the author(s) and / or other copyright owners and it is a condition of accessing these publications that users recognise and abide by the legal requirements associated with these rights.

Take down policy

The Research Portal is Queen's institutional repository that provides access to Queen's research output. Every effort has been made to ensure that content in the Research Portal does not infringe any person's rights, or applicable UK laws. If you discover content in the

Research Portal that you believe breaches copyright or violates any law, please contact openaccess@qub.ac.uk. 
Effects of autotomy compared to manual declawing on contests between males for females in the edible crab, Cancer pagurus: implications for fishery practice and animal welfare.

12 Claire McCambridge, Jaimie TA Dick and Robert W Elwood ${ }^{1}$

13

14 Institute for Global Food Security

15 School of Biological Sciences

16 Queen's University, Belfast

17 Northern Ireland, UK BT7 9BL

$19 \quad{ }^{1}$ Corresponding author r.elwood@qub.ac.uk

20 Tel: 07787939896

21 The authors contributed equally to this work.

22 
Abstract

29

In many decapod fisheries, claws are removed and the animal returned to the sea with the assumption that there is little impact on the fitness and welfare of the animal, or on the productivity of the population. Here, the impact of claw loss, by two methods of claw removal, is examined during competition between males for access to females in the crab, Cancer pagurus. Males induced to autotomize a claw showed little reduction in their competitive ability, however, those subject to the fishery practice of manual declawing showed a marked decrease in their competitive ability. Compared to autotomized males, these declawed crabs displayed activities that suggest an awareness of the wound caused by the appendage being twisted off and the data are consistent with an impaired welfare for these animals. They were also less likely to display to their opponent compared to autotomized crabs. Intact males showed high aggression towards declawed males, which showed low aggression in return. Further, declawed crabs showed particularly high levels of submissive acts. The declawed crabs thus rarely gained the female compared to autotomized crabs. The present study demonstrates that manual declawing has a major detrimental impact on fitness and welfare of edible crabs and we suggest that this method of harvesting should be replaced with induced autotomy of a single claw.

Key words: autotomy, Cancer pagurus, manual declawing, contests, welfare.

47

8

1 2

3

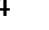




\section{Introduction}

Manual declawing of crabs is practiced in many fisheries, including the Southern Florida stone crab, Menippe mercenari, (Ehrhardt 1990), the North East Atlantic deepwater red crab, Chaceon affinis, the Southern Iberian fiddler crab, Uca tangeri, (Oliveira et al. 2000) and in Northern Europe, the edible crab, Cancer pagurus (Patterson et al. 2009). After declawing, the animal is released and the practice of manual declawing is defended because crabs may naturally autotomize a claw or walking leg, for example when grasped by a potential predator, and then regenerate the lost limb (Juanes and Smith 1995). It has thus been argued that manual declawing offers a sustainable resource within the fishery (Carroll and Winn 1989).

The fishery practice of manual declawing by twisting and breaking the limb from the body in the edible crab, however, typically breaks some of the exoskeleton of the main body around the point of articulation of the limb (Patterson et al. 2007). This causes a stress response that includes a marked elevation of glucose within 10 minutes and increased lactate within 1 minute. The ratio of glucose to glycogen altered significantly after 10 minutes, indicating mobilisation of glycogen energy stores typical of the crustacean stress response (Patterson et al., 2007). Claw ablation of the freshwater prawn, Macrobrachium rosenbergii, produced a similar increase in glucose (Manush et al. 2005). In the edible crab, however, induced autotomy, which results in a clean severance of the limb without damage to the adjacent exoskeleton, does not cause physiological stress (Patterson et al., 2007).

Manual declawing under experimental conditions also results in high mortality. In the stone crab, Menippe mercenari, $47 \%$ of individuals that had both claws removed died within $24 \mathrm{hr}$ and $28 \%$ died after a single claw removal (Davis et al. 1978). Patterson et al. (2007) found that wound sizes of manually declawed C. pagurus that died were larger than those that survived, suggesting that the extent of wounding is a major factor in crab mortality. Those that had claws removed by induced autotomy, had significantly lower mortality than did those manually declawed. A lower mortality rate was noted when claws were broken along the natural fracture plane in M. mercenaria (Simonson and Hochberg 1986) and mortality depended on the severity of the wound, and how the claw was broken off (Juanes and Smith 1995). 
Further, the loss of one or both claws by either method places crabs at a distinct disadvantage in terms of feeding. For example, although loss of one claw does not alter the feeding motivation of $C$. pagurus, it does decrease ability to feed on bivalves (Patterson et al. 2009). This reduced food choice due to claw loss is also seen in Cancer productus and Carcinus maenas, which are constrained to handling smaller prey (Elner 1980; Brock and Smith 1998) and growth and regeneration may be reduced (Savage and Sullivan 1978; Elner 1980; Juanes and Smith 1995; Seed and Hughes 1995; Brock and Smith 1998). Thus, claw loss can affect the long term fitness of these animals (Smallegange and Van Der Meer 2003).

In keeping with many other decapods, the claws of $C$. pagurus are sexually dimorphic, being larger in males, and are used during competition between males for access to females (Lee 1995). This dimorphism is even greater in fiddler crabs, Uca tangeri, in which the major claws of males are used for signalling to females to attract them to their breeding burrows and to defend their burrows from other males. The removal of this vital appendage biases the operational sex ratio towards females, as clawless males are treated as females by other males and females (Oliveira et al. 2000). Thus, removing the major claw of male fiddler crabs has potential consequences at the population level. In hermit crabs, Pagurus minutus and $P$. nigrofascia, males show precopular guarding of females and often fight intruder males to retain the female. Intruders with a naturally missing, presumably autotomized, major cheliped were as likely as intact intruders to escalate a contest but were less successful in gaining the female compared to intact males (Yasuda and Koga 2016, Yasuda et al. 2011). Deficits in contests for females have also been noted in other decapods that have missing chelae (Smith 1992; Daleo 2009). These studies, however, have only examined how claw loss affects contest behaviour and outcome and have not examined how the nature of claw loss might mediate contest behaviour, outcome and fitness.

It is expected that the loss of a major weapon will adversely affect contest performance in that damaged male when fighting an intact male (Arnott and Elwood 2009). This could be due to a decrease in how that damaged male assesses its own fighting ability, often called resource holding potential, RHP (Parker and Stuart 1976). In addition, it might reduce the intact opponent's estimation of the damaged male's RHP. It 
117 is likely, however, that there is a greater loss of RHP to the damaged male if the claw is 118 removed by manual declawing rather than by induced autotomy, because the former causes considerably more injury and physiological stress (Patterson et al. 2007). It is possible that the intact opponent could detect the greater injury caused by manual removal of its opponent's claw. Alternatively, it is possible that the intact male may simply detect the loss of the claw in its opponent and not the manner of that loss. By comparing the contests involving either manually declawed or autotomized males competing against intact males insights into the assessment processes during contests may be gained.

Two major practical concerns associated with claw harvesting in C. pagurus and other decapods are addressed. First, the practice might not be as benign to the population as previously suggested and thus future productivity may be compromised (Carroll and Winn 1989). Here, the fitness consequences of having a missing claw and on the nature of the claw loss of males competing for females is examined. If claw loss and the nature of claw loss impact fitness it would be expected that there would be differences in the ability to compete for key resources. Second, some methods of claw removal may affect the welfare of individual crabs more than others (Sherwin 2001; Patterson et al., 2007; Elwood et al. 2009). Thus, activities indicating an awareness (not necessarily conscious) of the wounds arising from declawing are recorded.

\section{Material and Methods}

\subsection{Collection, maintenance and experimental procedure}

Male and female $C$. pagurus of $140 \mathrm{~mm}-180 \mathrm{~mm}$ carapace width were collected by commercial fishermen in April and May 2012, using baited pots, in the Irish Sea, off the Ards Penisular of County Down, and maintained on deck in fish trays and baskets. Crabs were transported from the harbour slip at Portaferry, Co Down, Northern Ireland to the adjacent Queen's University Marine Laboratory (QML) in storage boxes.

Morphometric data were collected from each animal; sex, wet weight (g) and carapace width (cm), and the crab was tagged with 'Queen Bee' tags (Thorne, UK), small coloured plastic dots numbered 1-100, attached to the carapace with non-toxic, water proof hypoxy glue. Crabs were then maintained for 5 days to recover from the stress of capture (Patterson et al. 2007; Barrento et al. 2011) in outdoor 5500 litre circular, low 
147 profile water tanks (76cm depth, $175 \mathrm{~cm}$ diameter), with a continual supply of sand-filtered water piped directly from the sea $\left(8-9^{\circ} \mathrm{C}\right)$. Tanks were equipped with overflow outlets to allow for water circulation, and an air diffuser was used to aerate the water. To control feeding and provide shelter and protection crabs were kept in individual lidded storage boxes $(71 \mathrm{~cm}(\mathrm{~L}) \times 44 \mathrm{~cm}(\mathrm{~W}) \times 38 \mathrm{~cm}(\mathrm{H}))$, with approximately $20 \times 3 \mathrm{~cm}$ diameter ventilation holes for water and oxygen circulation. Approximately 10-13 boxes were kept in each outdoor tank. The outdoor tanks were kept covered and secured with blue/green coated woven polyethylene tarpaulins, to ensure minimum light intensity/disturbance. The crabs were not fed during this period.

Observations of contests were made in a tank (Figure 1) of 9.5mm thick plate glass measuring $80 \mathrm{~cm}(\mathrm{~L}) \times 50 \mathrm{~cm}(\mathrm{~W}) \times 50 \mathrm{~cm}(\mathrm{H})$. It comprised three chambers separated by removable rigid Perspex partitions ( $3 \mathrm{~mm}$ thick), blackened using marine paint (Krylon Fusion). These tank dividers were perforated ( $3 \mathrm{~cm}$ diameter holes) to allow the movement of water and any chemical cues released by the crabs, including haemolymph leaking from wounds, throughout the tank. A continuous supply of Strangford Lough sea water at approximately $9.5^{\circ} \mathrm{C}$ and air (via an Airstone (BiOrb)) was pumped into the tank.

Sand and small pebble substrate, collected from the Strangford Lough tidal area, was provided (approx. 3-4cm deep). The exterior rear and sides of the tank were also blackened using black marine paint. The area surrounding the tank was cordoned off using black plastic sheeting to control for light interference during the observation period. Red light (OSRAM Fireglow Effect 60W, 170 Lumen) was used to enable observations without natural and/or artificial light intrusion, and to obscure the observer. At the end of each observation, the sea water was drained from the tank, and refilled for the next subjects to eliminate chemical cues and leaked haemolymph.

For each replicate, two male crabs and one female crab were randomly selected for each contest. From these, one of the males was randomly selected (by drawing tokens from a cup) to have either the right or the left claw forcibly removed (manually declawed), or the male crab was induced to autotomize a claw. The other male crab and the female crab remained intact. The experimental replication was: intact $\underline{v}$ autotomy $n=34$; intact $\underline{v}$ manually declawed $n=26$ and animals were used only once. Manual declawing involved 
177 holding the body of the crab in one hand and grasping and sharply twisting the claw with 178 the other (Patterson et al. 2007). Autotomy involved making a small cut at the joint at the 179 top of the merus, the claw is then cast off by the crab at the joint that attaches to the body 180 (Patterson et al. 2007). Males were individually placed in the two small chambers and the 181 female in the large chamber (Figure 1), for one hour to acclimatise in red light. The tank 182 partitions were then removed and all three crabs were free to move throughout the tank. 183 Continuous recording, using a mounted digital camera above the tank, was used to 184 capture all occurrences of behaviour during the 60 minute observational period. The 185 186 were on top of the female in the typical guarding posture. Others remained next to the female, using a claw to hold her by the carapace or a leg, or the male placed a claw or walking legs on the female. Other winners simply stayed next to or in front of the female, but remained in physical contact. Females did not show resistance to the presence of the male. The contest losers were not in close proximity to the winning male or the female at the end of the contest. From preliminary observations, a number of activities were identified. These were classified into five broad categories, to avoid excessive analyses (Table 1). In addition, 'frothing' from the mouth parts was recorded as occurring or not immediately after the claw treatments were performed, before the crab was placed into the water. It was characterized by a bubbly foam coming out of the mouth parts. Further, when the non-intact males were first put into the individual sections of the observation arena, it was noted whether or not haemolymph was visible in the water. Finally, touching the wound by the non-intact crab, with its remaining claw and/or walking legs, was recorded during the 60 minute observational period.

\subsection{Ethical consideration}

No licence was required for this experiment because invertebrates other than cephalopods are not regulated under the UK Scientific Procedures Act. Nevertheless, sample sizes were kept as low as possible for contingency analyses, and fewer replicates were used in the treatment considered to be the more extreme, as recommended (Elwood 1991). Manual claw removal is an extreme procedure but one that is used in many fisheries on very large numbers of animals. It is possible that the data from the present 
study might guide future fisheries practice. On this basis the procedures used in the experiment were considered justified.

\subsection{Data Analyses}

Effects of claw loss and the nature of that loss on which animal initiated the contests, produced the first display, success in obtaining the female, and self-directed behaviour towards the wound of non-intact males, were analysed using contingency tests and/or binomial tests. Logistic regression was used to analyse the effect of relative size of contestants that were successful in obtaining the female. For the categories aggression, defensive, dominant and submission, the occurrence of each activity for each category was noted without respect to duration and totalled as the number of such acts in each category. An activity was deemed to have occurred twice (or more) if separated by the occurrence of another activity.

We used a one between and one within repeated measures ANOVA to determine the effects of claw removal procedure (between observations factor: declawed or autotomized) and claw removal status (within observations factor: missing claw or intact) on the agonistic behaviours. We also included the interaction term between these factors. Repeated measures are used because two animals within one contest do not act independently of each other (see Briffa and Elwood 2010 for statistical rationale). All data in the ANOVAs were $\log _{10}(x+1)$ transformed to improve normality. Multiple tests were not adjusted by Bonferroni correction because that has been criticized for too easily rejecting real effects (Nakagawa 2004). All statistical analyses used the Statview package.

\section{Results}

\subsection{Initiation, display and success.}

Of the 60 staged encounters, 57 resulted in one male obtaining the female but in 6 of these there was no overt interaction between the males. In the other 51 cases the males interacted before one obtained the female and, of these replicates, intact crabs were more likely than non-intact crabs to win the contest (binomial $35 \underline{v} 16, \mathrm{P}=0.003$ ). 
235

236

237

238

239

240

241

242

243

244

245

246

247

248

249

250

251

252

253

254

255

256

257

258

259

260

261

262

263

264

265

Autotomized males were as likely to get the female as intact males (binomial $14 \vee 17$, $\mathrm{P}=0.72$ ), but manually declawed crabs were less likely to obtain females compared to intact crabs (binomial $2 \vee 18, P=0.0004$ ). Further, autotomized crabs were more likely to win the contest compared to manually declawed crabs (autotomized 14/31 $\underline{v}$ manually declawed $2 / 20, G=7.76, P=0.005)$. Logistic regression showed that relative size of competing crabs did not affect whether or not the intact crab won the female $\left(X^{2}=0.008\right.$,

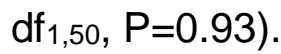

Of the 51 contests, 44 involved cheliped displays by one or both opponents. Intact crabs were more likely than non-intact crabs to be the first to display (binomial $33 \vee 11$ $\mathrm{P}=0.0013)$. Nevertheless, intact crabs did not differ from autotomized crabs in displaying first (binomial $17 \vee 10, P=0.24$ ), but were more likely to display first if placed with a manually declawed male (binomial $16 \vee 1$ ). Further, autotomized crabs were significantly more likely than declawed crabs to initiate displays (autotomized 10/27 v manually declawed 1/17, $\left.X^{2}{ }_{1}=5.5, P=0.02\right)$.

There was no difference between autotomized crabs and manually declawed crabs in the probability of initiating the contest (autotomized 14/31 $\underline{v}$ manually declawed $7 / 20$, $\mathrm{G}=0.52, \mathrm{P}=0.47$ ). Contest initiators were more likely to win than were non-initiators (binomial $35 \underline{v}$ 16, $\mathrm{P}=0.003$ ). Further, intact initiators were more likely than non-intact initiators to win the contest (intact 25/31 $\underline{v}$ non-intact 10/20, $G=5.26, P=0.022$ ). Autotomized crabs that initiated the contest against their intact opponent were more likely to win compared to manually declawed crabs that initiated the contest against their intact opponent (autotomized 9/14 $\underline{v}$ manually declawed 1/7, G=5.07, $P=0.024$ ).

\subsection{Aggression}

There was no overall difference between contests involving autotomized or manually declawed crabs in the number of aggressive activities $\left(F_{1,49}=0.42, P=0.5\right.$; Figure 2). Intact crabs exhibited more aggressive behaviour than did the non-intact crabs $\left(F_{2,49}=65.13, P<0.0001\right.$; Figure 2$)$. Importantly, there was a significant interaction effect between type of contest (involving autotomized or manually declawed), and the intact/non-intact status of the contestants $\left(F_{2,49}=9.80, P=0.003\right.$; Figure 2$)$. This is because intact crabs competing against manually declawed crabs showed a particularly high 
266 number of aggressive activities, whereas the manually declawed crab showed the least 267 number (Fig 2).

\subsection{Defence}

More defensive activities occurred in contests involving manually declawed crabs 271 than those with autotomized crabs ( $F_{1,49}=4.22, P=0.045$; Figure 3$)$ and non-intact crabs 272 displayed considerably more defensive behaviour compared to intact crabs $\left(F_{2,49}=24.62\right.$, $273 \mathrm{P}<0.0001$; Figure 3), but there was no significant interaction effect between these factors $274 \quad\left(F_{2,49}=2.87, P=0.096\right)$.

275

\subsection{Dominance}

Contests involving autotomized or manually declawed crabs did not differ in the 278 overall number of dominance activities $\left(F_{1,49}=3.70, P=0.06\right.$; Figure 4$)$ and intact crabs exhibited more dominance activities than did non-intact crabs $\left(F_{2,49}=14.53, P=0.0004\right.$; Figure 4), but there was no significant interaction effect $\left(F_{2,49}=1.77, P=0.19\right)$.

\subsection{Submissive}

A higher number of submissive activities occurred in contests involving manually declawed crabs than those involving autotomized crabs ( $F_{1,49}=9.32, P=0.004$; Figure 5). Non-intact crabs exhibited more submissive behaviour than did intact crabs $\left(F_{2,49}=22.47\right.$, $\mathrm{P}<0.0001$; Figure 5). Importantly, there was a significant interaction effect $\left(F_{2,49}=8.19\right.$,

$287 \quad \mathrm{P}=0.006$; Figure 5). This arose because of the exceptionally high number of submissive 288 activities performed by the manually declawed crabs compared to the other groups.

\subsection{Other observations}

Crabs that were manually declawed were more likely to froth at the mouth than 291 autotomized crabs (manually declawed 17/23 $\underline{v}$ autotomized 9/34, G=12.88, P<0.001), 
292 haemolymph from the wound was visible in the water in more replicates with manually declawed crabs than autotomized crabs (manually declawed 16/23 $\underline{v} 6 / 34, G=16.07$, $\mathrm{P}<0.0001$ ), and manually declawed crabs were more likely to touch the wound with its remaining claw or front walking legs than did autotomized crabs (manually declawed 15/23 $\underline{v}$ autotomized 7/34, G=15.93, $P<0.0001$ ).

\section{Discussion}

Although intact crabs were more successful than were non-intact crabs in competing for females, those induced to autotomize a claw were considerably more successful than crabs that were manually declawed. Indeed, autotomized crabs fared no worse than intact crabs when just those contests were examined. That is, it is not the absence of a claw that reduces the ability of a male to obtain a female, at least under the present conditions, rather it is the manner of claw loss. Manual declawing clearly places males under a severe intra-specific competitive disadvantage. Negative effects of claw loss have been noted in other studies (Sekkelsten, 1988; Abello et al., 1994), but the manner of claw loss has received little or no attention with regard to such competition. To understand how the outcome of contests is influenced by the nature of the claw loss, the activities used in the competitive process are considered.

Activities that occur early in the encounter should indicate how the males assess themselves in terms of RHP rather than indicating how the opponent perceives them Elwood and Arnott 2012). Intact crabs were more likely than non-intact crabs to initiate the contest by moving towards the opponent, however, manually declawed and autotomized crabs did not differ in the probability of initiation of contests. Initiating the contest gives an advantage to that crab because those that initiated were more likely to obtain the female. Autotomized crabs that initiated, however, were more likely to win access to the female than were manually declawed crabs, suggesting that the latter did particularly poorly in the ensuing fight.

Intact males were also more likely than non-intact males to be the first to display. Here, there was a marked effect of the nature of claw loss because, while the autotomized crabs were as likely as the intact to display first, the manually declawed crabs very rarely 
322 displayed first. This suggests that it is not the lack of a claw that is dissuading the crab to 323 engage in display but, rather, it was due to the poor condition of the declawed crabs 324 (Patterson et al. 2007). Further, the raising up and stretching out of the claw or claws is 325 likely to be energetically expensive (Doake et al. 2010) and perhaps beyond the capability 326 of a manually declawed crab.

Manually declawed crabs were more likely than autotomized crabs to lose haemolymph in amounts that could be seen in the water. Frothing at the mouth was also more common in declawed crabs than in autotomized crabs, such frothing in crabs having been attributed to stress (Deshai 2012). Manual declawing also results in elevated concentrations of lactate compared to intact and autotomized crabs (Patterson et al. 2007). High lactate concentrations during contests causes fatigue (Briffa and Elwood 2005) and alters behaviour such as defensive actions (Stoner 2012). Manually declawed crabs may therefore be unable to engage in fighting, and may withdraw from the contest based on assessment of their internal state.

Manually declawed crabs appeared to be aware of their wound, as indicated by their much higher incidence of touching the wound compared to autotomized crabs. Although not part of the recording protocol, a number of manualy declawed crabs showed a 'shudder' response when touching the wound. The remaining claw or a leg was brought to the wound site and either inserted directly into the wound or probed the edges of the wound site. The 'shudder' response was only observed when the wound was being 342 touched and the crab's body was seen to give a little shake or tremble. Touching at the site of the application of a noxious stimulus has been noted in glass prawns (Barr et al. 2008) and hermit crabs (Appel and Elwood 2009) and is considered to indicate an awareness of the location of a wound. Shaking of a claw has been noted following injection of formalin into that appendage (Dyuizen et al. 2012), but the present study is the first to note shaking/shuddering of the entire body.

Some manually declawed crabs shielded their wound by positioning the remaining claw in front of the wounded area. This protected the wound from contact by the intact opponent, but impeded the ability of wounded crabs to engage in the normal activities seen in crab fights. These observations indicate that declawed crabs were aware (not necessarily conscious) of their wound and that the wound resulted in marked changes in 
behaviour that are not merely reflexive but consistent with the idea of pain (Elwood 2011; Sneddon et al. 2014). These crabs also appeared to be in poor condition and incapable of effective competition. How this resulted in losing the encounter may be determined by examining the specific groups of activities that comprise the competitive interaction i.e. aggression, defence, dominance and submission.

Intact crabs were more aggressive than non-intact crabs and they were particularly aggressive when encountering a manually declawed crab rather than one that had autotomized. In return, the manually declawed crabs showed very few aggressive acts. It is possible that the intact crab was responding to either the wound or the behaviour of declawed opponents and increasing aggression above that normal for crab fights. Alternatively, the intact crab might be fighting normally without information being gathered about the wound or behaviour of the non-intact crab. It is clear, however, these contests are highly asymmetric with respect to the number of aggressive acts shown. Intact crabs also showed more acts of dominance than did the non-intact crabs, but the lack of a significant statistical interaction shows that, in contrast to aggressive acts, this was not affected by the nature of claw loss. With dominance activities, there is no evidence that the intact male can discriminate between the two types of claw loss in an opponent. Thus, the behaviour of the intact crab does not distinguish whether or not these contests are based on self-assessment, where each contestant acts according to its own abilities, or by mutual assessment, where each incorporates information about the ability of the opponent (Elwood and Arnott 2012).

Defensive acts were shown less often by the intact crabs compared to non-intact crabs. Both types of claw loss resulted in high numbers of defensive acts in the affected males and the lack of a significant statistical interaction indicates that the nature of claw loss did not have a marked effect in defensive behaviour. Crabs with a missing claw also showed more submissive acts than did those with both claws. In this case, submissive acts were much more frequent by manually declawed compared to autotomized crabs. This is evidence that the declawed crabs are attempting to avoid the agonistic encounter, presumably because they are aware of their poor condition. Thus, judging from the observation on submission, manually declawed crabs are not attempting to fight but rather 
are attempting to limit damage. Thus, the data on the non-inctact crabs indicates selfassessment is affecting how they compete (sensu Taylor and Elwood 2003).

It is clear that intact crabs were more motivated to fight compared to those missing a claw. Further, autotomized crabs were more motivated to engage in a fight than manually declawed crabs. This is evidenced by crabs that were autotomized showing fewer submissive acts and winning more contests than manually declawed crabs. It is possible that autotomized crabs engaged in dishonest signalling to convey a greater aggressive intent and fighting ability, a common trait among crustaceans (Steger and Caldwell 1983; Backwell et al. 2000; Elwood et al. 2006; Laidre 2009). Indeed, male hermit crabs that lack the major claw (presumably by autotomy) are just as likely to escalate contests for females, but were much less likely to win than intact intruders (Yasuda and Koga 2016). In the mud crab, Cyrtograpsus angulatus Dana, crabs missing claws by induced autotomy were also able to win contests when competing against intact crabs (Daleo 2009).

One surprise in the current study was that body size did not have a significant effect of the outcome of contests because body size has been shown to be important in numerous other taxa (Arnott and Elwood 2009). In the present study, however, a narrow range of crab sizes was employed as no crab below the minimum legal landing size of $140 \mathrm{~mm}$ carapace width was included in the experiment. With a wider size range of opponents those crabs with a missing claw might effectively compete against much smaller opponents. Thus, if autotomized animals are released in the sea they would encounter a broader range of crabs than in the experiment and might have an increased chance of winning a contest for females, as well as other resources, when facing much smaller opponents. Further, it is possible that manually declawed crabs might also fare better with much smaller opponents. That is not to suggest that these crabs might do well if released because previous studies have shown a high mortality of manually declawed crabs (Patterson et al. 2007). It is important to note that in this experiment a maximum of one claw was removed whereas in some fisheries two may be removed. The consequences of losing both claws by manual declawing would be severe from the point of view of survival (Davis et al. 1978) and even if lost by autotomy, there would be major 
413 detrimental effects on ability to feed (Juanes and Smith 1995) and undoubtedly on 414 competitive ability.

\section{Conclusion.}

It is clear that the ability to compete against intact crabs is severely affected by the nature of claw removal. Crabs that have a single claw manually removed by twisting have very poor success in male-male contests compared to those that lose a claw by induced autotomy. This major fitness impact is likely due to the haemolymph loss seen immediately after manual claw removal but much less after induced autotomy. Wounds are much larger after manual declawing (Patterson et al. 2007) and these crabs showed the stress response of frothing from the mouth (Deshai 2012). Manual declawing rather than autotomy also results in rapid increases in haemolymph lactate and glucose that is typical of a marked physiological stress response (Patterson et al. 2007). Further, the observation of repeated touching and picking at the wound after manual declawing, as well as guarding of wounds, suggests an awareness of the wound. Thus, there are concerns for the welfare of crabs subject to manual declawing (Elwood 2011). There must also be concerns that returning crabs to the sea after manual declawing will not enhance population sustainability, because of the loss in competitive ability, the loss of feeding ability (Patterson et al. 2009) and the substantial mortality (Patterson et al. 2007) seen in these animals. It is suggested that manual declawing is discontinued in those fisheries in which it still occurs. An alternative would be training fishermen to induce autotomy in one claw, followed by return of the crab to the sea.

\section{Acknowledgments}

This work was funded by the Department of Agriculture and Rural Development 439

\section{References}

Abello, P., Warman, C.G., Reid, D.G., Naylor, E., 1994. Chela loss in the shore crab Carcinus maenas (Crustacea: Brachyura) and its effect on mating success. Mar. Biol. 
121, 247-252.

Appel, M., Elwood, R.W., 2009. Motivational trade-offs and potential pain experience in hermit crabs. Appl. Anim. Behav. Sci. 119,120-124.

Arnott, G., Elwood, R.W., 2009. Assessment of fighting ability in animal contests. Anim. Behav. 77, 991-1004.

Barr, S., Laming, P., Dick, J.T.A., Elwood, R.W., 2008. Nociception or pain in a decapod crustacean? Anim. Behav. 75, 745-751.

Barrento, S., Marques, A., Vaz-Pires, P., Nunes, M.L., 2011. Cancer pagurus (Linnaeus, 1758) physiological responses to simulated live transport: Influence of temperature, air exposure and AQUI-S®. J. Therm. Biol., 36, 128-137.

Backwell, P.R.Y., Christy, J.H., Telford, S.R., Jennions, M.D., Passmore, J., 2000. Dishonest signalling in a fiddler crab. Proc. Roy. Soc. London B: Biol. Sci., 267, 719-724. Briffa, M., Elwood, R.W., 2005. Rapid change in energy status in fighting animals: causes and effects of strategic decisions. Anim. Behav., 70, 119-124.

Briffa, M., Elwood, R.W 2010. Repeated measures analysis of contests and other dyadic interactions: Problems of semantics, not statistical validity. Anim. Behav. 80, 583-588.

Brock, R.E., Smith, L.D., 1998. Recovery of claw size and function following autotomy in Cancer productus (Decapoda: Brachyura). Biol. Bull. 194, 53-62.

Carroll, J.C., Winn, W.R., 1989. Species Profiles. Life Histories and Environmental Requirements of Coastal Fishes and Invertebrates (Pacific Southwest). Brown Rock Crab, Red Rock Crab, and Yellow Crab. US Fish and Wildlife Service. Biology Report 82 (11.117).

Daleo, P., 2009. The effect of size and cheliped autotomy on sexual competition between males of the mud crab Cyrtograpsus angulatus Dana. Mar. Biol. 156, 269-275.

Davis, G. E., Baughman, D. S., Chapman, J. D., MacArthur D., Price, A. C., 1978. Mortality associated with declawing stone crabs, Menippe mercenaria. National Park Service, report T-552. Home-stead, FL: South Florida Research Center. 20 pp. 
470 Deshai, R. B., Katore, B. P., Shinde V. D., Ambore N. E. 2012 Behavioral study of female 471 crab Brytelphusa guerini under acute stress of dimethoate. Int. Multidis. Res. J. 2, 1-4

472 Doake, S., Scantlebury, M., Elwood, R.W., 2010. The costs of bearing arms and armour 473 in the hermit crab Pagurus bernhardus.Anim. Behav. 80, 637-642.

474 Dyuizen, I.V., Kotsyuba, E.P., Lamash, N.E., 2012. Changes in the nitric oxide systemin 475 the shore crab Hemigrapsus sanguineus (Crustacea, Decapoda) CNS inducedby a 476 nociceptive stimulus. J. Exp. Biol. 215, 2668-2676.

477 Ehrhardt, N.M., 1990. Mortality and catchability estimates for the stone crab (Menippe 478 mercenaria) in Everglades National Park. Bull.Mar. Sci., 46, 324-334.

479 Elner, R.W., 1980. Lobster gear selectivity - a Canaidian overview. Canaidian Tech. Rep. 480 Fisheries Aquat. Sci., 932, 78-83.

481 Elwood, R.W., 1991. Ethical implications of studies on infanticide and maternal 482 aggression in rodents. Anim. Behav. 42, 841-849.

483 Elwood, R.W., 2011. Pain and suffering in invertebrates? Ilar J., 52, 175-184.

484 Elwood, R.W., Arnott, G. 2012. Understanding how animals fight with Lloyd Morgan's canon. 485 Anim. Behav. 84, 1095-1102.

486 Elwood, R.W., Barr, S., Patterson L., 2009 Pain and stress in crustaceans? Appl. Anim. 487 Behav. Sci. 118, 128-136.

488 Elwood, R.W., Ponthanikat, R.M.E., Briffa, M., 2006. Honest and dishonest displays, 489 motivational state and subsequent decisions in hermit crab shell fights. Anim. Behav. 72, $490 \quad 853-859$.

491 Juanes, F., Smith, L.D., 1995. The ecological consequences of limb damage and loss in 492 decapod crustaceans : a review and prospectus. J. Exp. Mar. Biol. Ecol. 193, 197-223.

493 Laidre, M., 2009. How often do animals lie about their intentions? An experimental test. 494 Am. Nat. 173, 337-346.

495 Lee, S.Y. \& Seed, R., 1992. Ecological implications of cheliped size in crabs: some data 496 from Carcinus maenas and Liocarcinus holsatus. Mar Ecol Prog Ser, 84, 151-160. 
497 Manush, S.M., Pal, A.K., Das, T., Mukherjee, S.C., 2005. Dietary high protein and vitamin 498 C mitigate stress due to chelate claw ablation in Macrobrachium rosenbergii males. 499 Comp. Bio. Phys. - A, 142, 10-18.

500 Nakagawa, S., 2004. A farewell to Bonferroni: the problems of low statistical power and 501 publication bias. Behav. Ecol. 15, 1044-1045.

502 Oliveira, R.F., Machado, J.L, Jordão, J.M., Burford, F.L., Latruffe, C., Mcgregor, P.K., 503 2000. Human exploitation of male fiddler crab claws: behavioural consequences and 504 implications for conservation. Anim. Cons. 3, 1-5.

505 Parker, G.A., Stuart, R.A., 1976. Animal behavior as a strategy optimizer: evolution of 506 resource assessment strategies and optimal emigration thresholds. Am. Nat. 110, 10555071076.

508 Patterson, L., Dick, J.T., Elwood, R.W., 2007. Physiological stress responses in the edible 509 crab, Cancer pagurus, to the fishery practice of de-clawing. Mar. Biol. 152, 265-272.

510 Patterson, L., Dick, J.T., Elwood, R.W., 2009. Claw removal and feeding ability in the 511 edible crab, Cancer pagurus: Implications for fishery practice. Appl. Anim. Behav. Sci. 512 116, 302-305.

513 Savage, T., Sullivan, J.R., 1978. Growth and claw regeneration of the stone crab, 514 Menippe mercenaria. Florida Mar. Res. Pub. 32, 1-23.

515 Seed, R., Hughes, R.N., 1995. Criteria for prey size-selection in molluscivorous crabs 516 with contrasting claw morphologies. J. Exp. Mar. Biol. Ecol., 193, 177-195.

517 Sekkelsten, G.I., 1988. Effect of handicap on mating success in male shore crabs 518 Carcinus maenas. Oikos 51, 131-134.

519 Sherwin, C.M., 2001. Can invertebrates suffer? Or, how robust is arguement-by-analogy. 520 Anim. Welfare, 10, S103-118.

521 Simonson, J.L., Hochberg, R.J., 1986. Effects of air exposure and claw breaks on survival 522 of stone crabs Menippe mercenaria. Trans. Am. Fisheries Soc. , 115, 471-477.

523 Smallegange, I.M., Van Der Meer, J., 2003. Why do shore crabs not prefer the most 
524 profitable mussels? J. Anim. Ecol. 72, 599-607.

525 Smith, L.D., 1992. The impact of limb autotomy on mate competition in blue crab 526 Callinectes sapidus. Oecologia 89, 494-501.

527 Sneddon, L.U., Elwood R.W., Adamo S.A.,, Leach MC. 2014. Defining and assessing 528 animal pain. Anim. Behav. 97,202-212.

529 Steger, R., Caldwell, R.L., 1983. Intraspecific deception by bluffing: a defense strategy of 530 newly molted stomatopods (Arthropoda: Crustacea). Science, 221, 558-560.

531 Stoner, A.W., 2012. Assessing stress and predicting mortality in Economically Significant 532 Crustaceans. Rev. Fisheries Sci., 20, 111-135.

533 Taylor, P., Elwood, R.W. 2003. Mis-measure of animal contests. Anim. Behav. 65, 1195-1202.

534 Yasuda, C.I., Koga, T. 2016. Do weaponless males of the hermit crab Pagurus minutus 535 give up contests without escalation? Behavior of intruders that lack their major cheliped 536 in male-male contests. J. Ethol. in press.

537 Yasuda, C.I., Suzuki, Y., Wada, S., 2011. Function of the major cheliped in male-male 538 competition in the hermit crab Pagurus nigrofascia. Mar. Biol. 158, 2327-2334.

539

540

541

542

543

544

545

546

547

548 
Table 1 Male competitive activities grouped into broad categories.

561

562 563 and one of four other activities follows.

564 Activity

565 Approach

566

567

568

569

570

571

572

573 Aggressive activities include 'displays', incurring low costs, followed by an 'attack', and

574 finally a 'fight', that presumably incurs the highest costs with the potential for injury to both 575 crabs.

\section{Description}

One opponent approaches the other opponent, decreasing the distance between the contestants. This is followed by: Opponents face each other; no contact, One opponent makes contact with other opponent, Opponents face each other, claws in contact, or One opponent uses claw(s) to stroke other opponent.
Mutual Alignment
Contact
Contact Alignment
Claw Stroke

\section{Aggressive behaviour}




\section{Activity}

Display

Threat Display

Extend

Lunge

Manus Contact

Pull In

Mutual Push

Carapace Grasp

Grip

Anterior Strike

Wound Grasp

Repeated Grasp

Grip Back

Flip

\section{Defensive behaviour}

Defensive activities include one crab attempting to repel and/or escape from its opponent.
Activity

Retreat

Withdraw

\section{Description}

One opponent extents claws out towards other opponent, pinchers open; no contact.

One opponent raises body high on walking legs, extends claws, directed towards other opponent.

One opponent swipes claw towards other opponent; no contact.

One opponent, claw open and extended, thrusts body forward at opponent; brief contact.

Opponents face each other in threat display; claws in contact, pinchers open.

One opponent uses claws to pull opponent, decreasing distance between individuals.

One opponent uses claw(s) to push against other opponent, other opponent pushes back.

One opponent grasps and holds other opponents carapace. One opponent uses claw(s) to grip other opponent, pinching/crushing observed.

One opponent uses claw(s) to grip anterior region of carapace of other opponent.

One opponent uses claw(s) to grasp other opponents wound site.

One opponent repeatedly grabs and grips opponent; vigorous pushing and pinching/crushing observed. One opponent uses claw(s) to return the grip of other opponents' claw(s), pinching/crushing observed. With interlocked claws or by grasp of carapace, one opponent is lifted from the substrate and held above opponent.

\section{Description}

One opponent retreats rapidly from the other opponent. One opponent leaves the area of the other opponent, increasing the distance between the contestants. 
616 Struggle

617

618 Push Away

619

620 Dismount

621

622

623

624

625

626

627

628

629

630

631

632

633

634

635

636

637 638 crab.

639

640

641

642

643

644 Crawl under

645

646

647

648

649

650
Activity

Rise up

Pushdown

Tap

Mount

Push

Free
Activity

Motionless

Submission
One opponent struggles to free itself from other opponents grasp.

One opponent uses claw(s) to push other opponent away, creating distance between the opponents.

One opponent climbs off other opponent.

\section{Dominant behaviour}

Dominant behaviour was observed when one crab appeared to exert control over its opponent, typically with its opponent engaging in subordinate behaviour (below).

\section{Description}

One opponent rises up on legs.

One opponent uses claw(s) to push down on other opponent's carapace.

One opponent uses claw(s) to 'tap' on other opponent's carapace.

One opponent crawls on top of the other opponent.

One opponent uses claws and/or body to push against other opponent; contact.

One opponent releases other contestant from grasp.

\section{Submissive behaviour}

This was observed by crabs typically in response to dominant behaviour by the opposing

\section{$\underline{\text { Description }}$}

One opponent freezes body position; no overt sign of movement or response.

Opponent draws claws and walking legs in and under body, lowers body.

One opponent attempts to position itself under other opponent's body. 
651

652

653

654

655

656 
Fig 1

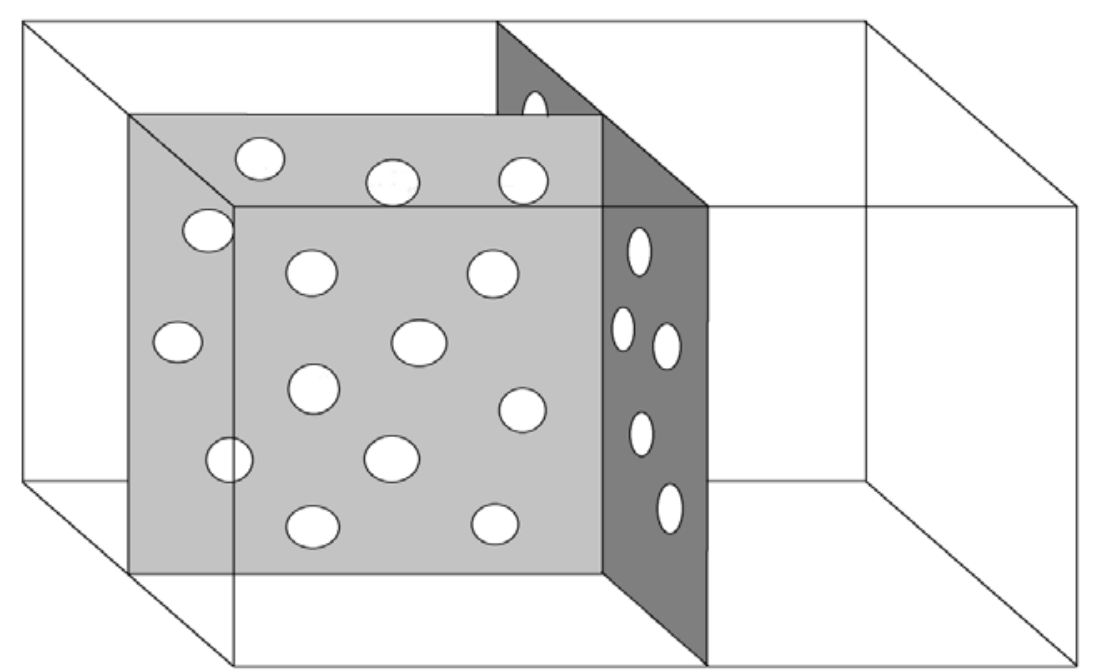


Fig 2

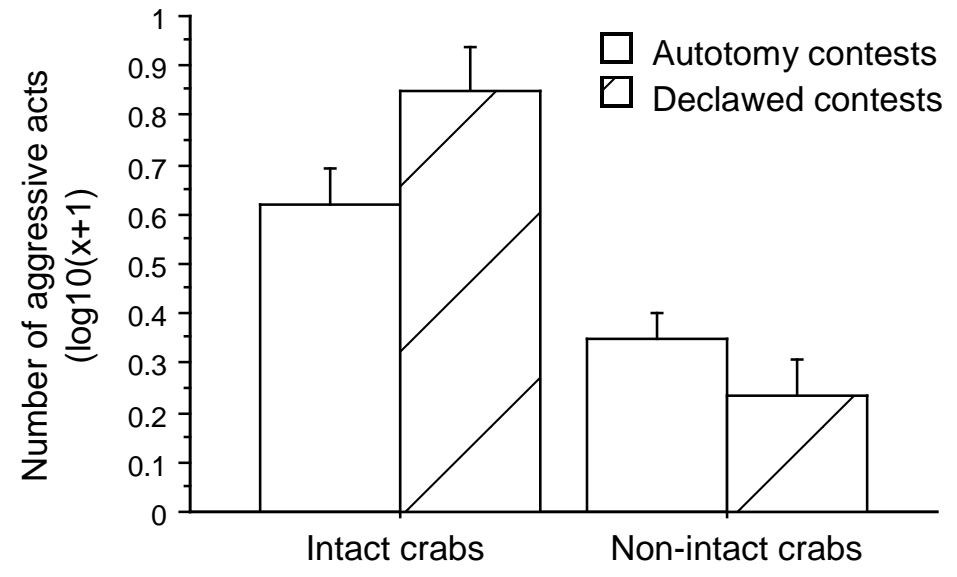


Fig 3

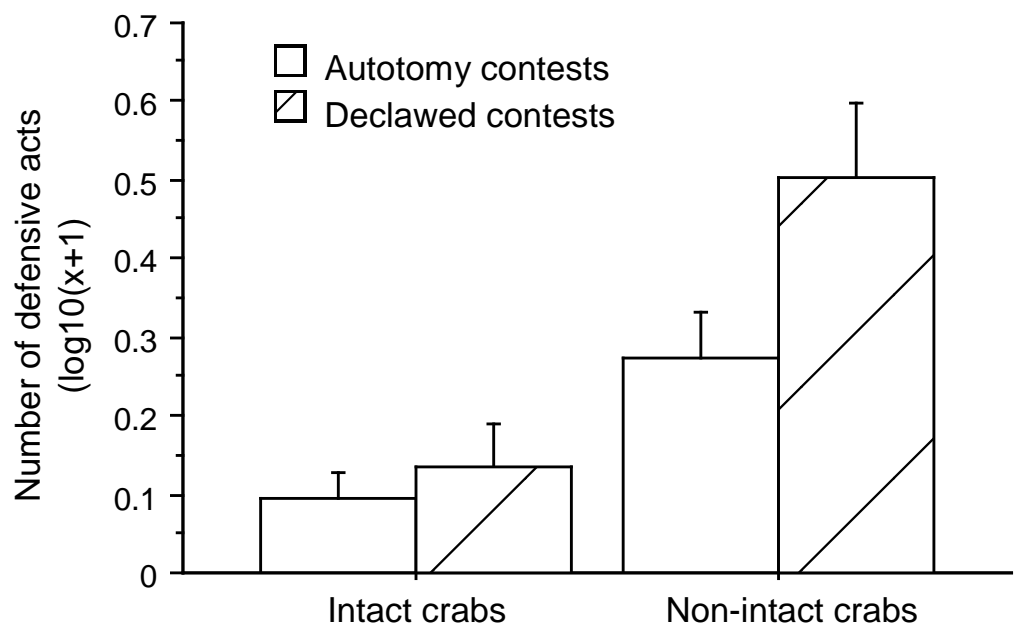


Fig 4

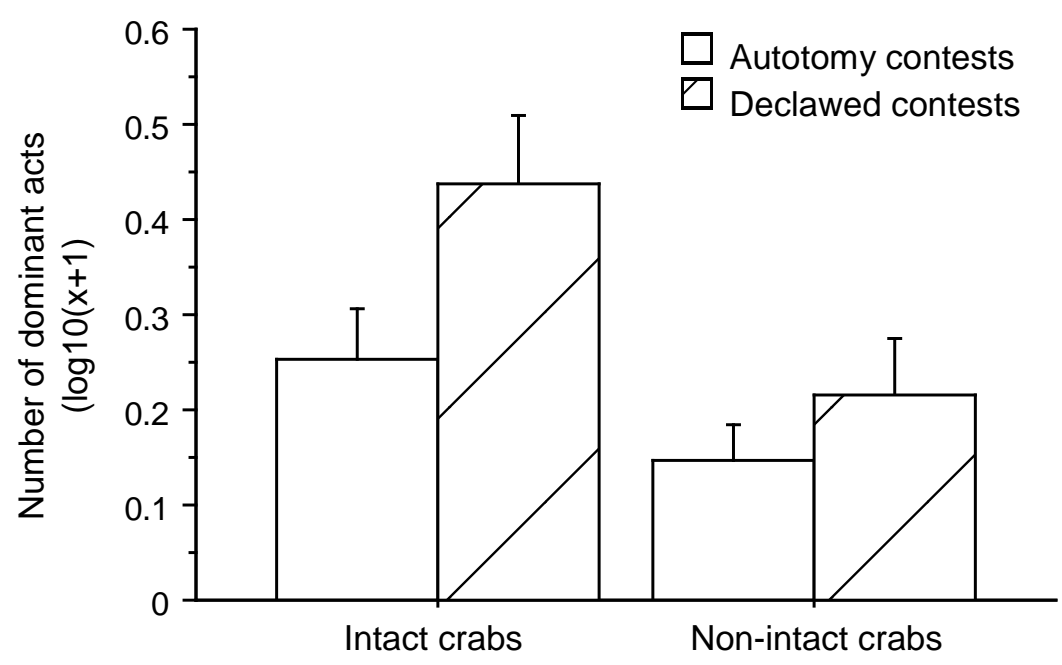


Fig 5

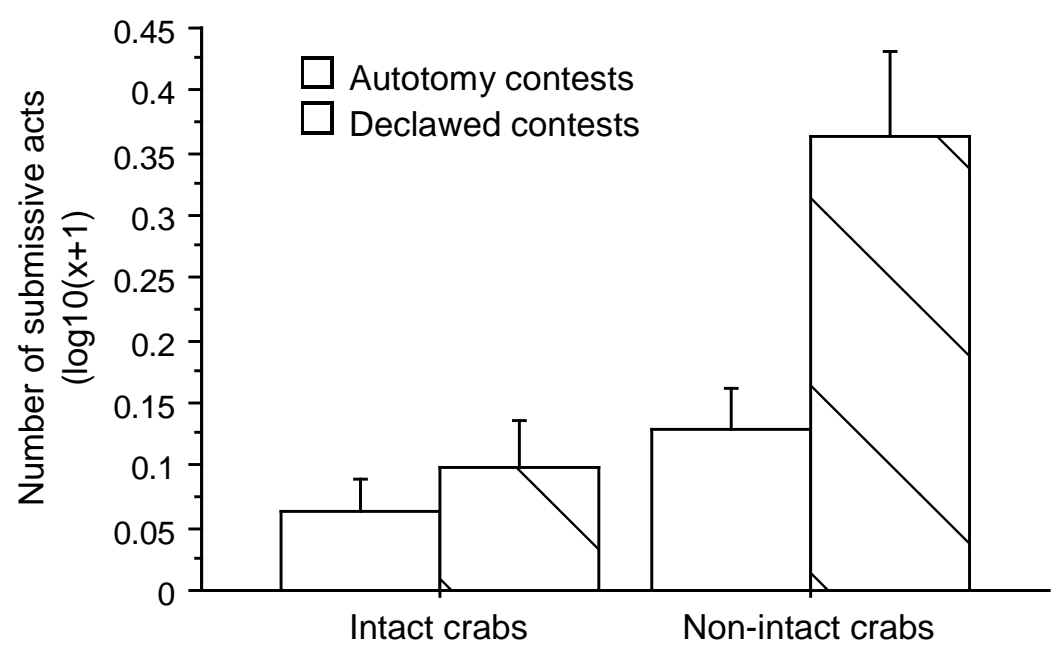


Figure legends

Figure 1 Schematic of observational tank, showing removable partitions that creates three temporary holding chambers.

Figure 2 Mean (+S.E) number of aggressive acts displayed by intact and non-intact crabs involving contests of autotomized and manually declawed crabs.

Figure 3 Mean (+S.E) number of defensive acts displayed by intact and non-intact crabs involving contests of autotomized and manually declawed crabs.

Figure 4 Mean (+S.E) number of dominant acts displayed by intact and non-intact crabs involving contests of autotomized and manually declawed crabs.

Figure 5 Mean (+S.E) number of submissive acts displayed by intact and non-intact crabs involving contests of autotomized and manually declawed crabs. 